Cornell University

College of Agriculture and Life Sciences

Viticulture and Enology Program

\title{
Effects of concentration prior to cold-stabilization on anthocyanin stability in Concord grape juice
}

\author{
Kristin Alongi, Olga Padilla-Zakour, and Gavin Sacks \\ Journal of Agricultural and Food Chemistry (2010) 58: 11325-11332 \\ http://pubs.acs.org/doi/abs/10.1021/jf102223f
}

Background. Concord grape juice is known for its deep purple-red color, which is due to a class of pigments called anthocyanins. Like all grape juices, Concord juice is high in tartaric acid, which can precipitate as potassium bitartrate crystals ("cream of tartar") during refrigerationan undesirable outcome for consumers. To prevent crystallization in the bottle, Concord juices and nearly all other grape juices and wines can be cold-stabilized, i.e., held at near-freezing temperatures for days to induce potassium bitartrate formation. Unfortunately, $20 \%$ to $40 \%$ of anthocyanins in juice will bind to the precipitating crystals and will be lost from the juice. We evaluated several juice processing methods to determine their effect on anthocyanins and resulting juice color.

Experimental design. Finger Lakes Concord grapes were harvested at 14 to $16^{\circ} \mathrm{Brix}$. Six

Figure 1

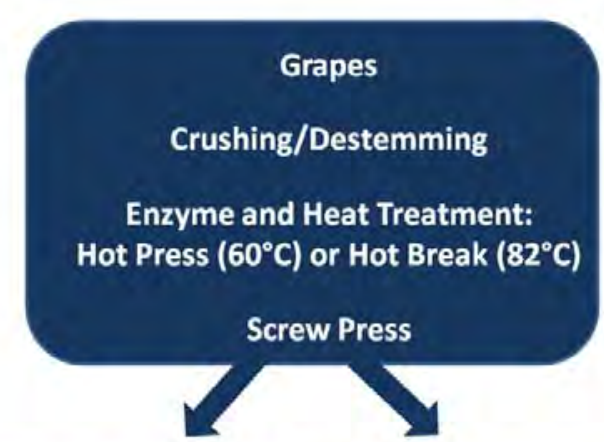

Standard Concentrate

Cold Storage/

Bitartrite Precipitation

Concentration to

$59^{\circ}$ Brix

Storage

Reconstitution to $16^{\circ}$ Brix
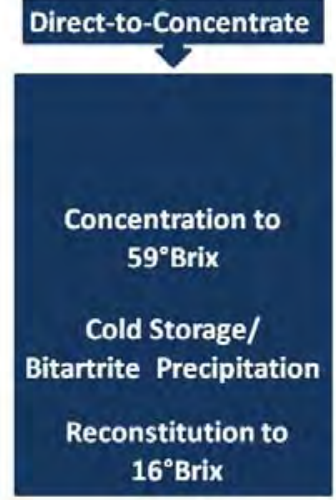

processing methods were tested (the overall scheme is presented in Fig. 1). In standard concentrate processing, concentration of juice to $59^{\circ}$ Brix occurs after cold-stabilization. In direct-toconcentrate processing, the juice is concentrated to $59^{\circ}$ Brix before cold-stabilization. We also tested the effects of hot press (heating to $82^{\circ} \mathrm{C}$ and depectinization before pressing) and hot break (heating to $60^{\circ} \mathrm{C}$ and depectinization before pressing). After processing, juice was pasteurized and stored for two weeks at $2^{\circ} \mathrm{C}$. Juice color intensity was measured by absorbance at $520 \mathrm{~nm}$, the primary wavelength absorbed by anthocyanins. Color stability was assessed at 0, 2, 9, and 16 weeks. Microscopy was used to examine the bitartrate crystals precipitated during coldstabilization. Anthocyanin profiles in finished juices were compared by high performance liquid 
chromatography (HPLC).

Results. The direct-to-concentrate method produced the highest juice color, retaining the juice color intensity of the freshly pressed juice and $62 \%$ higher color (measured by absorbance) than standard concentrate juice. There were no significant differences in juice color between hot press and hot break methods. The color loss in the standard concentrate method was caused by coprecipitation of anthocyanins with the bitartrate crystals, a phenomenon illustrated by the microscope images in Figure 2.

Figure 2. Standard processing of Concord juice resulted in bitartrate crystals with red, coprecipitating anthocyanins (left). Direct-to-concentrate processing (right) did not.
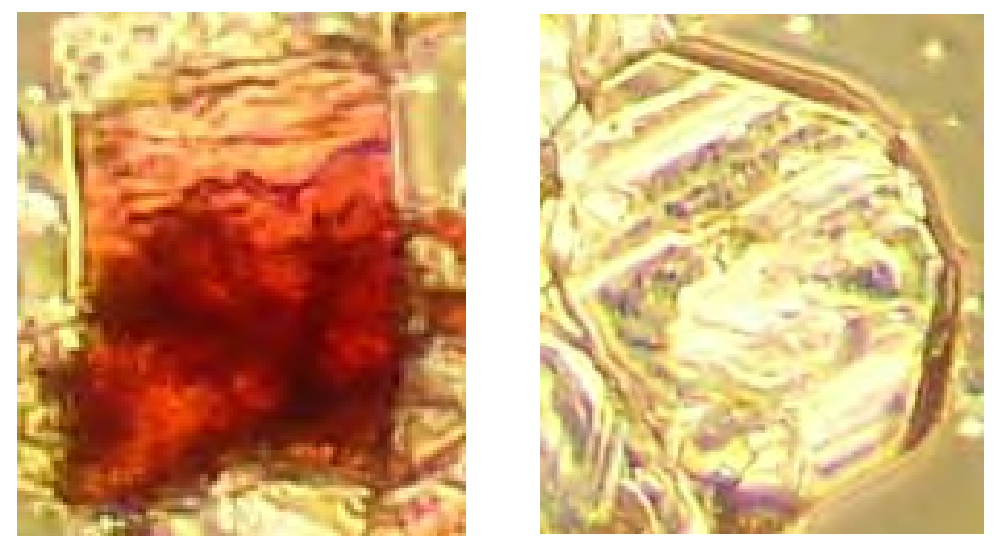

Unexpectedly, chromatographic analysis of the anthocyanins that remained in the juice after cold-stabilization suggested a theory for the co-precipitation. The types of anthocyanins most likely to be lost during cold-stabilization were those that had a positive charge at juice $\mathrm{pH}$ (3.13.2). We hypothesized that the lower $\mathrm{pH}$ of the concentrate (2.5) compared to the juice may neutralize the negative surface charge of bitartrates and decrease the likelihood of anthocyanin co-precipitation and color loss.

\section{Conclusions:}

- Anthocyanins will precipitate with potassium bitartrate crystals during cold-stabilization, but losses can be avoided by first converting the juice to a concentrate.

- The difference in $\mathrm{pH}$ between juice and concentrate may be crucial for the observed differences in anthocyanins losses.

The bottom line: Future work is necessary to determine if this work can be adapted to reduce anthocyanin losses during cold-stabilization of juice and wine without relying on concentration. 